\title{
ANALYSIS OF THE MEASUREMENT UNCERTAINTY OF A NEW MEASUREMENT FLEXURE CALIBRATION SET-UP
}

\author{
K. Geva ${ }^{1}$, H. Kahmann ${ }^{2}$, C. Schlegel ${ }^{3}$, R. Kumme ${ }^{4}$ \\ 1, 2, 3, 4 Physikalisch-Technische Bundesanstalt, Braunschweig, Germany \\ ${ }^{1}$ kai.geva@ptb.de, ${ }^{2}$ holger.kahmann@ptb.de,${ }^{3}$ christian.schlegel@ptb.de, ${ }^{4}$ rolf.kumme@ptb.de
}

\begin{abstract}
:
A measurement flexure calibration set-up is presented in this paper. The measurement flexures under test are part of a new $5 \mathrm{MN} \cdot \mathrm{m}$ standard torque machine measurement system at the PTB. The calibration set-up can create transversal forces up to $200 \mathrm{~N}$ and bending moments up to $100 \mathrm{~N} \cdot \mathrm{m}$ and respectively up to $150 \mathrm{~N} \cdot \mathrm{m}$ torque moments simultaneously. The measurement uncertainty budget of the set-up is investigated in a theoretical analysis.
\end{abstract}

Keywords: measurement uncertainty budget; bending moment; transversal force; multicomponent measurement

\section{INTRODUCTION}

At the PTB a new $5 \mathrm{MN} \cdot \mathrm{m}$ standard torque machine (STM) is built to calibrate torque transducers [1]. The $5 \mathrm{MN} \cdot \mathrm{m}$ STM consists of an actuator side for generating calibration moments (torque as well as bending moments) and a measurement side for measuring the applied load. Both sides have a lever to which a torque transducer under test is flange-mounted. The measurement side contains six measurement flexures (MF) to receive the lever forces axially. There are two types of MF: two MF which measure torque (TMMF) and four MF which measure bending moments (BMMF). The BMMF's tangential forces and torque moments share around $3 \%$ of the overall $5 \mathrm{MN} \cdot \mathrm{m}$ torque moment. Due to MF's displacement, parasitic forces and moments are inevitable. The knowledge of these moments and forces are essential to define the overall measurement uncertainty of the standard torque machine. To achieve a torque measurement uncertainty below $0.5 \%$ it is necessary to evaluate the MF in a special calibration set-up. The calibration is designed to provide a measurement with an uncertainty lower than $1 \%$. The following paper explains the set-up to calibrate the MF and analyses the expected measurement uncertainty. Finally, critical influences on the measurement uncertainty must be identified and concepts or measurements must be defined to reduce key measurement uncertainty influences.

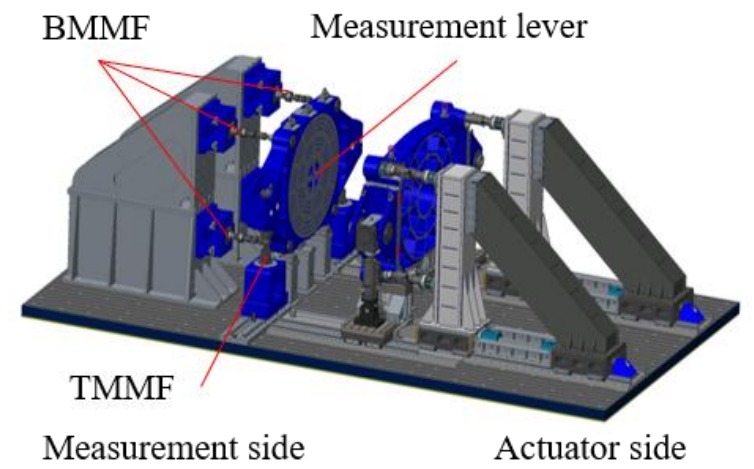

Figure 1: $5 \mathrm{MN} \cdot \mathrm{m}$ Standard Torque Machine (STM)

\section{MEASUREMENT FLEXURE CALIBRATION SET-UP}

\subsection{Load Scenario of BMMF in $5 \mathrm{MN} \cdot \mathrm{m} \mathrm{STM}$}

Table 1: Forces on BMMF at $5 \mathrm{MN} \cdot \mathrm{m}$ STM (FEAnalysis)

\begin{tabular}{|l|c|c|c|}
\hline & $\boldsymbol{F}_{\boldsymbol{x}}$ in N & $\boldsymbol{F}_{\boldsymbol{y}}$ in N & $\boldsymbol{F}_{\boldsymbol{z}}$ in N \\
\hline BM 1 & 175 & -5 & -10624 \\
\hline BM 2 & 175 & 5 & 10624 \\
\hline BM 3 & 176 & 6 & 10614 \\
\hline BM 4 & 176 & -6 & -10614 \\
\hline
\end{tabular}

Table 2: Moments on BMMF at $5 \mathrm{MN} \cdot \mathrm{m}$ STM (FEAnalysis)

\begin{tabular}{|l|c|c|c|}
\hline & $\boldsymbol{M}_{\boldsymbol{x}}$ in N·m & $\boldsymbol{M}_{\boldsymbol{y}}$ in N·m & $\boldsymbol{M}_{\boldsymbol{z}}$ in $\mathbf{N} \cdot \mathbf{m}$ \\
\hline BM 1 & 68 & -73 & -128 \\
\hline BM 2 & -68 & -73 & -128 \\
\hline BM 3 & 68 & 74 & -113 \\
\hline BM 4 & -68 & 74 & -113 \\
\hline
\end{tabular}

The MF calibration scenario of the set-up must match the applied load combination occurring in the $5 \mathrm{MN} \cdot \mathrm{m}$ STM. A FE-analysis of the measurement side under the load of $5 \mathrm{MN} \cdot \mathrm{m}$ was performed to analyse the load scenario within the machine. Table 1 and Table 2 show the load applied on to the BMMF. All transversal forces are around $176 \mathrm{~N}$ and they are tangential from the lever's point of view. 
The moment generated by these tangential forces add up to the overall torque applied to the measurement lever of the $5 \mathrm{MN} \cdot \mathrm{m} \mathrm{STM}$ and must be considered in the uncertainty budget of the $5 \mathrm{MN} \cdot \mathrm{m} \mathrm{STM}$. The axial force is almost 100 times higher than the transversal force. Therefore, the transversal force cannot be measured by strain gauges but must be determined by measuring the displacement with an interferometer. The rigidity can be derived and used for calculating the forces and moments applied on BMMF when measuring the displacement in the $5 \mathrm{MN} \cdot \mathrm{m}$ STM during calibration. The FE-analysis indicates there is a constant ratio between applied tangential force and accompanying bending moment and torque moment respectively at all load steps. Bending moment divided by transversal force is 0.56 and torque divided by transversal force is 0.73 . Thus, the lever arms' lengths should meet these ratios to simplify the calibration procedure. Two load scenarios are applied at the calibration set-up. Load scenario 1 (LS1) is a combined result of a transversal force and a bending moment (BM). Load scenario 2 (LS2) is characterized by a transversal force which generates a torque moment (TM).

\subsection{Calibration Set-up}

Figure 2 and Figure 3 depict the calibration set-up for BMMF in both load scenarios. In both scenarios load is applied on top of each measurement flexure where the MF is connected to the measurement lever. There, a cantilever for each scenario is attached to an adapter at the MF. The LS1 cantilever consists of a horizontal and a vertical part. At the end of the vertical cantilever part the force introduction (FI BM) is aligned to the MF middle.

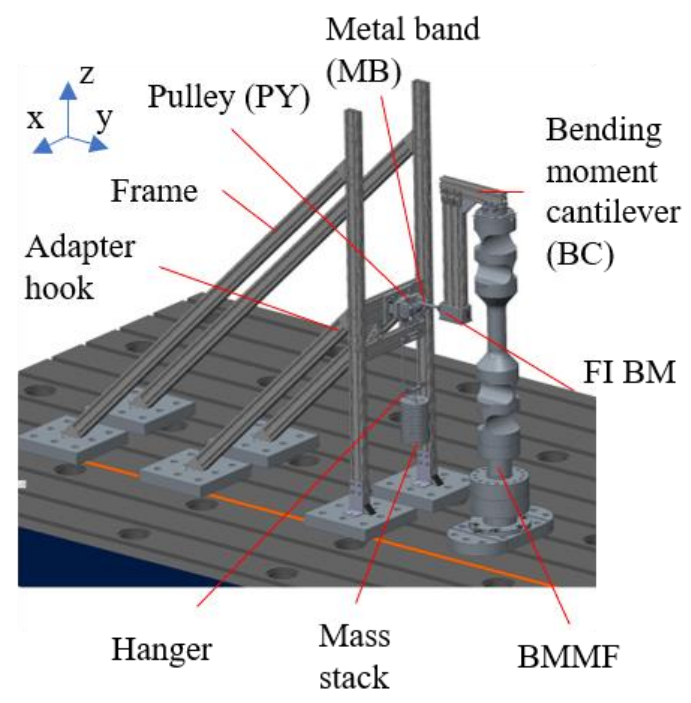

Figure 2: BMMF calibration set-up for LS1

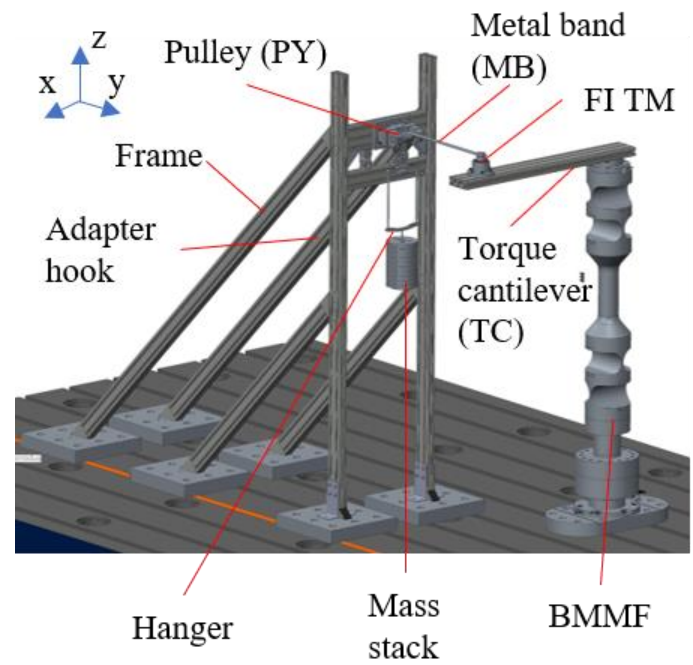

Figure 3: BMMF calibration set-up for LS2

There, the metal band (MB) is attached to a clamp and is aligned parallel to the MF top flange where the reference pivot point (PP) lies. The LS2 cantilever has only a horizontal part. At the end of the cantilever there is a shank supported by roll bearings the force is introduced to (FI TM).

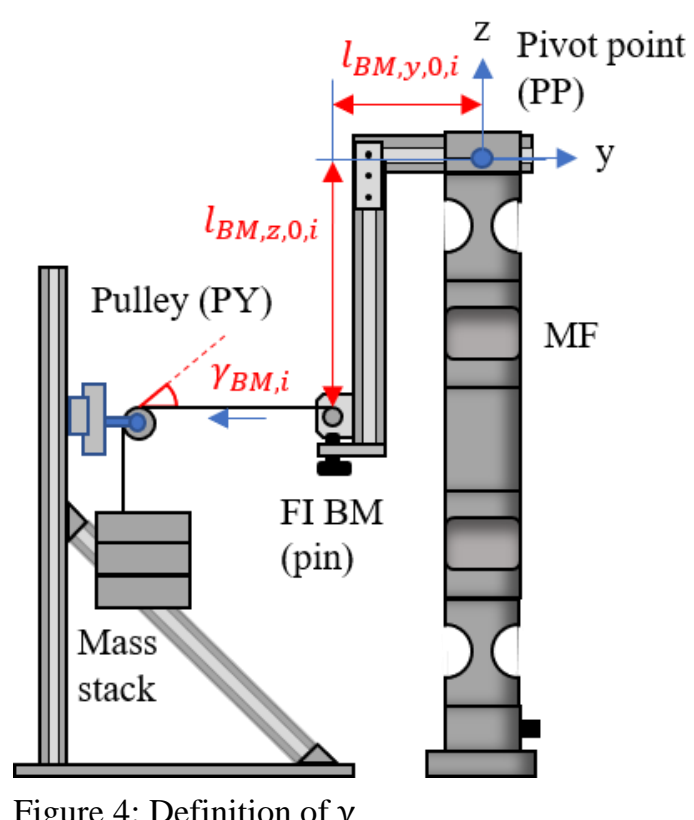

Force introduction LS1 (FI BM)

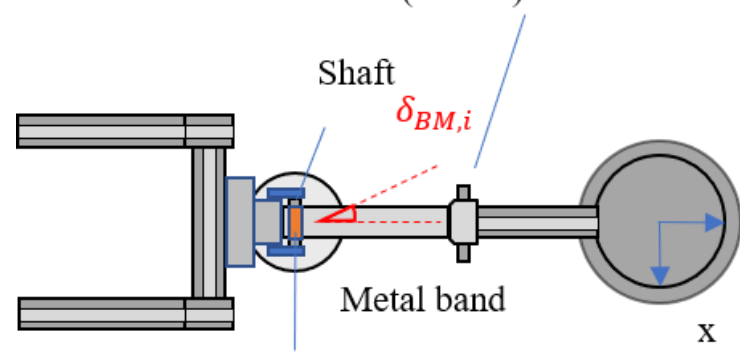

Linear bushing (LB)

Figure 5: Definition of $\delta$ 
The force is created via calibrated mass disks. For force application a thin metal band of $80 \mu \mathrm{m}$ thickness is used for determining the position of force application and to avoid bending moments. As the measurement flexures are erected vertically the gravitational force of the mass stack must be redirected by a pulley. For reasons of metal band alignment, the pulley is placed on a z-cross table. To compensate displacement in $\mathrm{x}$-direction a linear bushing (LB) is installed on a bar. Also, the metal band can rotate with minimal friction on the linear bushing. A mass stack up to $200 \mathrm{~N}$ is chosen to cover the full calibration range. The disks are laid manually onto a hanger which applies its force onto another clamp attached to the metal band.

\section{MEASUREMENT UNCERTAINTY BUDGET}

\subsection{Measurement Function}

Table 3 lists all the uncertainty influence parameter that are necessary to characterise the measurement uncertainty of the calibration set-up. There are two model equations to characterise the calibration load all influence parameters are derived from. The parameters will be analysed later.

The model equation for the force vector at FI is

$\vec{F}_{i}=\left(\begin{array}{c}\sin \gamma \\ \cos \gamma \cos \delta \\ \sin \delta\end{array}\right) \cdot F_{i}$.

The absolute value of the calibration force $F_{i}$ is

$$
\begin{aligned}
& F_{i}=\left(m_{i, d}+m_{\mathrm{hg}}+m_{\mathrm{hk}}+m_{\mathrm{vb}}+m_{\mathrm{bo}}\right) . \\
& g_{\mathrm{loc}} \cdot\left(1-\frac{\rho_{\mathrm{A}}}{\rho_{m}}\right)+\Delta F_{\mathrm{PM}}-\Delta F_{\mathrm{R}, \mathrm{LB}}-\Delta F_{\mathrm{R}, \mathrm{TC}} .
\end{aligned}
$$

The model equation for the moment vector at $\mathrm{PP}$ is

$$
\vec{M}=\left(\begin{array}{l}
l_{0, x} \\
l_{0, y} \\
l_{0, z}
\end{array}\right) \times \vec{F}_{i} .
$$

For LS1 a bending moment (BM) is applied

$$
\begin{aligned}
& M_{x, i}=\left(l_{\mathrm{BM}, 0, y} \cdot \sin \delta_{\mathrm{BM}}-l_{\mathrm{BM}, 0, z} \cdot\right. \\
& \left.\cos \gamma_{\mathrm{BM}} \cos \delta_{\mathrm{BM}}\right) \cdot F_{i}+M_{x, 0} .
\end{aligned}
$$

For LS2 a torque moment (TM) is applied

$$
\begin{gathered}
M_{z, i}=\left(l_{\mathrm{TM}, 0, x} \cdot \cos \gamma_{\mathrm{TM}} \cos \delta_{\mathrm{TM}}-l_{\mathrm{TM}, 0, z}\right. \\
\left.\cdot \sin \gamma_{\mathrm{TM}}\right) \cdot F_{i} .
\end{gathered}
$$

\subsection{Influence Quantities}

The influences are described in the following section. Finally, the total measurement uncertainty budget for the transversal force, the bending moment and the torque is presented.
Table 3: List of uncertainty influence parameters

\begin{tabular}{|c|l|}
\hline Parameter & Description \\
\hline$F_{i}$ & Transversal force for calibration \\
\hline$M_{x, i}$ & $\begin{array}{l}\text { Bending moment (BM) for LS1 } \\
\text { calibration }\end{array}$ \\
\hline$M_{x, 0, i}$ & $\begin{array}{l}\text { Bending moment (BM) due to } \\
\text { weight of LS1 cantilever }\end{array}$ \\
\hline$M_{z, i}$ & $\begin{array}{l}\text { Torque moment (TM) for LS2 } \\
\text { calibration }\end{array}$ \\
\hline$M_{z, \mathrm{TT}, i}$ & $\begin{array}{l}\text { Torque moment (TM) for LS2 } \\
\text { calibration, measured by a torque } \\
\text { transducer }\end{array}$ \\
\hline$\gamma$ & Vertical metal band inclination \\
\hline$\delta$ & Horizontal metal band inclination \\
\hline$l_{\mathrm{BM}, 0} / l_{\mathrm{TM}, 0}$ & LS1/ LS2 lever arm \\
\hline$m_{i, d}$ & Mass disk per load step $i$ \\
\hline$m_{\mathrm{hg}}$ & Hanger mass \\
\hline$m_{\mathrm{hk}}$ & Adapter hook mass \\
\hline$m_{\mathrm{vb}}$ & Vertical band mass \\
\hline$m_{\mathrm{bo}}$ & Band overlap mass \\
\hline$g_{\mathrm{loc}}$ & Local gravity \\
\hline$\rho_{\mathrm{A}}$ & Air density \\
\hline$\rho_{m}$ & Mass density \\
\hline$\Delta F_{\mathrm{PM}}$ & $\begin{array}{l}\text { Force disturbance caused by } \\
\text { pendulum motion }\end{array}$ \\
\hline$\Delta F_{\mathrm{R}, \mathrm{LB}}$ & $\begin{array}{l}\text { Force disturbance caused by linear } \\
\text { bushing friction }\end{array}$ \\
\hline$\Delta F_{\mathrm{R}, \mathrm{TC}}$ & $\begin{array}{l}\text { Force disturbance caused by TM roll } \\
\text { bearing friction (only LS2) }\end{array}$ \\
\hline & \\
\hline & \\
\hline & \\
\hline &
\end{tabular}

\section{Mass Disks and Density}

The laboratory for solid mechanics at PTB provides calibrated disks for special force calibration procedures. In this case, it consists of a set of $5 \mathrm{~N}, 10 \mathrm{~N}$ and $20 \mathrm{~N}$ disks $\left(m_{i, d}\right)$ which can be stapled manually onto a hanger $m_{\mathrm{hg}}$. Furthermore, a small hook adapter $m_{\mathrm{hk}}$ and the metal band $m_{\mathrm{vb}}$ must be considered. The uncertainty of these adapting elements is unknown and therefore estimated much higher than the other elements. Table 4 lists all mass disks with their mass, uncertainty and density.

Table 4: List of mass disks for $200 \mathrm{~N}$

\begin{tabular}{|l|r|l|}
\hline Mass disk & \multicolumn{1}{|l|}{ Mass in g } & $\begin{array}{l}\text { Density } \\
\text { in } \mathbf{~ k g} / \mathbf{m}^{3}\end{array}$ \\
\hline Hanger $m_{\mathrm{hg}}$ & $1019.248 \pm 0.005$ & $7950 \pm 140$ \\
\hline Mass 20 N & $2038.518 \pm 0.002$ & $7927 \pm 0.3$ \\
\hline Mass 10 N & $1019.261 \pm 0.001$ & $7927 \pm 0.3$ \\
\hline Mass 5 N & $509.630 \pm 0.005$ & $7927 \pm 0.3$ \\
\hline Metal band $m_{\mathrm{vb}}$ & $1.639 \pm 0.010$ & $7850 \pm 140$ \\
\hline Adapter hook $m_{\mathrm{hk}}$ & $145.092 \pm 0.050$ & $2850 \pm 140$ \\
\hline
\end{tabular}

\section{Band Overlap}

The band overlap happens when load is applied onto the hanger. The thin metal band will be deformed and get longer. There will be an overlap 
reaching over the pulley, resulting in additional mass as calibration load. The additional mass depends on the applied mass and is calculated by

$m_{\mathrm{bo}}=\rho_{\mathrm{MB}} \cdot A_{\mathrm{MB}} \cdot \Delta l_{\mathrm{bo}} \cdot$

Inserting Hooke's law, it yields

$m_{\mathrm{bo}}=\rho_{\mathrm{MB}} \cdot l_{\mathrm{FI}-\mathrm{PY}} \cdot \frac{F_{i}}{E_{\mathrm{MB}}}$.

The band overlap mass is shown in Table 5 .

Table 5: Additional mass caused by band overlap

\begin{tabular}{|c|c|}
\hline Load step & Mass in mg \\
\hline$m_{\mathrm{bo}, 50 \mathrm{~N}}$ & $10 \pm 5$ \\
\hline$m_{\mathrm{bo}, 100 \mathrm{~N}}$ & $20 \pm 10$ \\
\hline$m_{\mathrm{bo}, 150 \mathrm{~N}}$ & $30 \pm 15$ \\
\hline$m_{\mathrm{bo}, 200 \mathrm{~N}}$ & $40 \pm 20$ \\
\hline
\end{tabular}

\section{Local Gravity}

The local gravity is measured by the LeibnizUniversity Hannover at PTB. The calibration set-up will be placed near the $5 \mathrm{MN} \cdot \mathrm{m}$ STM in a new building, so the local gravity is not measured yet. For this analysis it is satisfactory to use the measured gravity in [2] at the $1 \mathrm{MN}-\mathrm{NME}$

$$
g_{\text {loc }}=9.812516 \pm 5 \cdot 10^{-6} \mathrm{~m} / \mathrm{s}^{2} \text {. }
$$

\section{Air Density}

The air density $\rho_{A}$ is calculated by

$$
=\frac{\rho_{\mathrm{A}}}{=0.34848 \cdot p_{\mathrm{A}}-0.009024 \cdot h_{\mathrm{A}} \cdot e^{0.0612 \cdot T_{\mathrm{A}}}}-.
$$

At the PTB solid mechanics laboratory the air temperature $T_{\mathrm{A}}$ is $(21 \pm 0.2){ }^{\circ} \mathrm{C}$. The average air pressure $p_{\mathrm{A}}$ is $(1013 \pm 2) \mathrm{hPa}$ and humidity $h_{\mathrm{A}}$ is $(42 \pm 5) \%$.

\section{Pendulum Motion}

The mass disks are placed manually onto the hanger which may cause swinging movements of the whole mass stack. To minimise pendulum motion, the hanger is clamped at the hanger bars while loading and unloading the mass disks. After the load step changes, the system must return to a balance where the signal caused by pendulum motion is less than $0.1 \mathrm{~N}$.

\section{Friction}

There are two components which cause friction. The pulley contains a z-cross table which carries a shaft. The shaft conducts a linear bushing. The bushing is shelled by a sleeve where the metal band is positioned. The linear bushing allows the movement of the metal band when loaded with low friction. The standard linear bushing from $\mathrm{BOSCH}$ REXROTH with a borehole diameter of $30 \mathrm{~mm}$ has a breakaway force of $6 \mathrm{~N}$. The second component effects only LS2 load scenario. The torque cantilever uses a metal band clamp that is attached to a shaft which rotates with the help of angular contact ball bearings. SCHAEFFLER provides the software tool BEARINX EASY FRICTION to estimate the friction. The first bearing yields a friction moment of $0.038 \mathrm{~N} \cdot \mathrm{m}$ and the second of $0.046 \mathrm{~N} \cdot \mathrm{m}$. The shaft diameter is $17 \mathrm{~mm}$ thus the overall breakaway force is $4.942 \mathrm{~N}$. Both friction forces must be measured in different set-ups. The cross table can be replaced by a tension force transducer. In this case an HBM Z30A PTB standard force transducer will be used featuring an uncertainty less than $3 \times 10^{-4}$. When measuring the tension at the point where the force introduction is meant to be, the working force will be reduced by the friction of the linear bushing. As the weight force of the calibrated mass is well-known, the friction can be measured for all load steps up to $100 \mathrm{~N}$. A variance of the linear bushing friction force is expected and must be tested experimentally but will not be quantified in this consideration. A similar approach will be performed to assess the roll bearings at the TM cantilever. Instead of using a force transducer a torque transducer is placed between cantilever adapter and BMMF top flange. It is fair to say that a common commercial flange torque transducer up to $100 \mathrm{~N} \cdot \mathrm{m}$ provides an uncertainty less than $1 \times 10^{-4}$. Comparing theoretically introduced torsion with the output of the interposed torque transducer reveals the friction of the roll bearing

$\Delta F_{\mathrm{R}, \mathrm{TC}, i}=F_{\mathrm{TC}, i}-\frac{M_{\mathrm{RTT}, i}}{l_{\mathrm{TM}, i}}$.

At all load steps the uncertainty for the so measured friction is less than $1 \%$.

\section{BM Cantilever Weight Moment}

The BM cantilever has a weight of $10.193 \mathrm{~kg}$ and a mass centre at a distance of $0.113 \mathrm{~m}$ from PP, thus leading to a bending moment offset at all load steps of $-11.291 \mathrm{~N} \cdot \mathrm{m}$. Various materials for different components, unknown density distribution and a complicated process to weigh the BM cantilever make an alternative way for estimation necessary. Between the BM cantilever adapter and the BMMF top flange a force transducer equipped with an additional bending moment measurement channel can be installed. Since the PTB lacks a test facility for bending moment, the measuring axis needs to be calibrated at the same BMMF calibration test stand. One will see later that calibrating bending moments lower than $20 \mathrm{~N} \cdot \mathrm{m}$ with a measurement uncertainty of $8 \%$ are achievable. A variance to the friction is expected but cannot be estimated in this paper satisfactorily and therefore will not be quantified. The maximum 
systematic deviation due to friction must be obtained experimentally.

\section{Thermal Expansion Coefficient}

The cantilever is built from ITEM-profiles made of an aluminium alloy. The expansion coefficient for aluminium is $24 \times 10^{-6} \mathrm{~K}^{-1}$ with an uncertainty of $4.8 \times 10^{-6} \mathrm{~K}^{-1}[3]$.

\subsection{Geometrical Characterisation}

The lever arm lengths $l_{\mathrm{BM}, y, 0}$ and $l_{\mathrm{BM}, z, 0}$ for bending moments and $l_{\mathrm{TM}, x, 0}$ and $l_{\mathrm{TM}, y, 0}$ for torque moments must be defined. Furthermore, the orientation of the applied transversal force vector must be characterised by the angles $\gamma$ and $\delta$ for both load scenarios at all load steps. It is planned to use an AT960 LR Absolute Tracker from LEICA to measure the geometrical elements. The uncertainty due to the different measurements performed by the tracker are estimated according to Hernla [3]. For each uncertainty influence quantity, he provides calculation tables based on technical specification parameters of the investigated coordinate measuring machine (CMM). Especially the $M P E$ (maximum permissible error) is used to quantify influences

$M P E=A+\frac{L}{K}$,

where $A$ is a constant and $K$ determines the uncertainty increase per length. The $M P E$ specification is valid only for LEICA's red ring reflectors which will be used strictly for the investigated measurements. For the used tracker, LEICA states $A$ is $15 \mu \mathrm{m}$ and $K$ is $166.7 \mathrm{~m} / \mu \mathrm{m}$. Hernla [3] uses two different model equations to estimate the uncertainty for the two specific tasks needed for measuring the mentioned geometry elements. The first equation describes the uncertainty of distance measurements

$$
\begin{array}{r}
L=\mid X_{1}-W_{1} \cdot k_{1}-\Delta R_{T 1}-X_{2}+W_{2} \cdot k_{2} \\
-\Delta R_{T 2} \mid-\Delta D_{\mathrm{C}}+\Delta L_{\mathrm{KMG}}+\Delta L_{T},
\end{array}
$$

where $X_{1}$ and $X_{2}$ are the coordinates for the elements measured. $W_{1}$ and $W_{2}$ are inclinations which need to be respected if the geometry element evaluated does not lie in the mass centre of the measurement points. $k_{1}$ and $k_{2}$ contain information about the coverage of the measure point range compared to the whole element measured. $\Delta R_{T 1}$ and $\Delta R_{T 2}$ are the deviation of the probe radius during calibration and are considered if a surface is measured. LEICA states the radius uncertainty of the reflector up to $2.5 \mu \mathrm{m}$. $\Delta D_{\mathrm{C}}$ is the deviation of the optical centre position which is less than $3 \mu \mathrm{m}$ for a red ring reflector. $\Delta L_{\mathrm{KMG}}$ is the geometrical deviation of the CMM for position measuring. $\Delta L_{T}$ is the deviation due to temperature for a CMM scale and for the measurement object. As the used tracker is temperature compensated and the length variation due to temperature is already considered, the term can be ignored here. For angle measurements he uses a second equation

$E_{O}=W_{E} \cdot k_{E}-W_{B} \cdot k_{B}+\Delta E_{\mathrm{KMG}}$,

where $W_{E}$ and $W_{B}$ are the inclinations two elements. $k_{E}$ and $k_{B}$ is again the coverage factor. $\Delta E_{\mathrm{KMG}}$ is the geometrical deviation of the CMM for inclination. Both equations list all possible uncertainty influences on the length or angle measurement but depending on the task not all quantities must be considered. For each influence quantity the uncertainty is measured by

$u_{i}=s_{i} \cdot b_{i} \cdot c_{i}$

with $s_{i}$ as standard deviation, $b_{i}$ as element parameter and $c_{i}$ as sensitivity coefficient. For all elements $X_{i}, W_{i}$ and $\Delta R_{T i}$ Hernla [3] suggests for conventional $\mathrm{CMM}$ to expect a deviation in the magnitude of $A / 3$. However, in the following calculation the full $M P E$-specification tolerance equation (11) because a mobile tracker is used instead of a conventional CMM. The MPE for a tracker measuring distance of $1 \mathrm{~m}$ yields $21 \mu \mathrm{m}$. $\Delta L_{\mathrm{KMG}}$ is approximated by

$a_{\Delta L_{\mathrm{KMG}}}=\frac{1}{K} \cdot \sqrt{L^{2}+l^{2}}$

with $L$ from the MPE specification and $l$ as the biggest length of one of the geometrical elements.

$\Delta E_{\mathrm{KMG}}$ is approximated by Hernla's [3] parallelism and rectangularity formula

$a_{\Delta E_{\mathrm{KMG}}}=\frac{2 L}{K}$

for a conservative estimation due to small expected angles. The factor $b_{i}$ contains the information how many measurement points are taken, how they are distributed over the measured element and what kind of geometry is extracted from the measurement. Based on best-fit calculation of geometrical elements Hernla [3] provides a calculation table for the most common measurement types. An FE-analysis was performed to obtain the displacements of all cantilevers and the pulley of the calibration set-up. From that, an estimation is made, how distances and angle change due to load application and presented in Table 6 .

\subsection{Measurement Uncertainty Budget}

The measurement uncertainty budgets are presented for transversal force, bending moment and torque at a nominal load of $50 \mathrm{~N}$ and $200 \mathrm{~N}$ in Table 7 . The force uncertainty budgets refer to the force in LS2 where the friction share is higher. The measurement uncertainty was calculated with the GUM workbench [4]. 
Table 6: Estimated measurement quantity for geometrical element

\begin{tabular}{|c|c|c|c|c|c|c|}
\hline Measurand & Unit & $\mathbf{0} \mathbf{N}$ & $50 \mathrm{~N}$ & $100 \mathrm{~N}$ & $150 \mathrm{~N}$ & $200 \mathrm{~N}$ \\
\hline$l_{\mathrm{BM}, y, 0}$ & $\mathrm{~mm}$ & 336.2 & 336.34 & 336.50 & 336.66 & 336.82 \\
\hline$l_{\mathrm{BM}, z, 0}$ & $\mathrm{~mm}$ & 563 & 562.96 & 562.91 & 562.86 & 562.81 \\
\hline$l_{\mathrm{TM}, x, 0}$ & $\mathrm{~mm}$ & 730 & 729.997 & 729.996 & 729.996 & 729.995 \\
\hline$l_{\mathrm{TM}, y, 0}$ & $\mathrm{~mm}$ & 0 & 0.249 & 0.492 & 0.735 & 0.978 \\
\hline$\gamma_{\mathrm{BM}}$ & $\circ$ & 0 & 0.013 & 0.033 & 0.051 & 0.069 \\
\hline$\gamma_{\mathrm{TM}}$ & $\circ$ & 0 & 0.001 & 0.002 & 0.002 & 0.004 \\
\hline
\end{tabular}

$\delta_{\mathrm{BM}}$ and $\delta_{\mathrm{TM}}$ are not listed for the estimated value at all load steps is zero degrees.

Table 7: Measurement uncertainty budget (MUB) for $F_{50 \mathrm{~N}}, M_{x, 50 \mathrm{~N}}$ and $M_{z, 50 \mathrm{~N}}$

\begin{tabular}{|c|c|c|c|c|c|c|}
\hline $\begin{array}{l}\text { Influence } \\
\text { quantity }\end{array}$ & $\begin{array}{c}\text { Index } \\
\boldsymbol{F}_{\mathrm{TM}, \mathbf{5 0} \mathbf{N}}\end{array}$ & $\begin{array}{c}\text { Index } \\
\boldsymbol{F}_{\mathrm{TM}, \mathbf{2 0 0} \mathbf{N}}\end{array}$ & $\begin{array}{c}\text { Index } \\
\boldsymbol{M}_{\boldsymbol{x}, \mathbf{5 0 ~ N}}\end{array}$ & $\begin{array}{c}\text { Index } \\
\boldsymbol{M}_{\boldsymbol{x}, \mathbf{2 0 0} \mathrm{N}}\end{array}$ & $\begin{array}{c}\text { Index } \\
\boldsymbol{M}_{\boldsymbol{z}, \mathbf{5 0} \mathbf{N}}\end{array}$ & $\begin{array}{c}\text { Index } \\
\boldsymbol{M}_{\boldsymbol{z}, \mathbf{2 0 0} \mathbf{N}}\end{array}$ \\
\hline$m_{d, i}$ & $39.4 \%$ & $41.9 \%$ & $5.7 \%$ & $7.0 \%$ & $31.0 \%$ & $32.7 \%$ \\
\hline$\Delta F_{\mathrm{PM}}$ & $3.4 \%$ & $0.2 \%$ & $0.5 \%$ & - & $2.7 \%$ & $0.1 \%$ \\
\hline$\Delta F_{\mathrm{R}, \mathrm{TC}}$ & $57.2 \%$ & $58.0 \%$ & - & - & $45.0 \%$ & $45.2 \%$ \\
\hline$\gamma_{\mathrm{BM} / \mathrm{TM}}$ & - & - & $0.7 \%$ & $0.7 \%$ & $4.5 \%$ & $4.6 \%$ \\
\hline$\delta_{\mathrm{BM} / \mathrm{TM}}$ & - & - & $92.3 \%$ & $92.3 \%$ & $16.8 \%$ & $17.4 \%$ \\
\hline$M_{x, 0}$ & - & - & $0.8 \%$ & $0.0 \%$ & - & - \\
\hline
\end{tabular}

$m_{\mathrm{BO}, i}, g_{\mathrm{loc}}, \rho_{m}, p_{\mathrm{A}}, h_{\mathrm{A}}, T_{\mathrm{A}}, l_{\mathrm{BM}, y, 0,50 \mathrm{~N}}, \Delta F_{\mathrm{R}, \mathrm{LB}}, l_{\mathrm{BM}, z, 0,50 \mathrm{~N}}, l_{\mathrm{TM}, x, 0,50 \mathrm{~N}}, l_{\mathrm{TM}, y, 0,50 \mathrm{~N}}$ and $\alpha_{\mathrm{W}}$ are not listed because they are less significant in this context.

Table 8: Measurement uncertainty for each load step

\begin{tabular}{|c|c|c|c|c|c|c|c|c|}
\hline $\begin{array}{l}\text { Load } \\
\text { step }\end{array}$ & $\begin{array}{l}F_{B M} \\
\text { in } \mathbf{N}\end{array}$ & $\begin{array}{c}u_{F_{B M}} \\
\text { in } \mathbf{N}\end{array}$ & $\begin{array}{l}\boldsymbol{F}_{T M} \\
\text { in } \mathbf{N}\end{array}$ & $\begin{array}{l}u_{F_{T M}} \\
\text { in } \mathbf{N}\end{array}$ & $\begin{array}{c}M_{x} \\
\text { in } \mathbf{N} \cdot \mathbf{m} \\
\end{array}$ & $\begin{array}{c}\boldsymbol{u}_{M_{x}} \\
\text { in } \mathbf{N} \cdot \mathbf{m}\end{array}$ & $\begin{array}{c}M_{z} \\
\text { in } \mathbf{N} \cdot \mathbf{m}\end{array}$ & $\begin{array}{c}\boldsymbol{u}_{M_{z}} \\
\text { in } \mathbf{N} \cdot \mathbf{m} \\
\end{array}$ \\
\hline $50 \mathrm{~N}$ & 45.5 & $\pm 0.4( \pm 0.9 \%)$ & 40.5 & $\pm 0.6( \pm 1.5 \%)$ & 14.0 & $\pm 0.9( \pm 6.4 \%)$ & 28.7 & $\pm 0.5( \pm 1.7 \%)$ \\
\hline $100 \mathrm{~N}$ & 95.5 & $\pm 0.9( \pm 0.9 \%)$ & 90.5 & $\pm 1.4( \pm 1.5 \%)$ & 41.8 & $\pm 1.9( \pm 4.5 \%)$ & 64.0 & $\pm 1.1( \pm 1.7 \%)$ \\
\hline $150 \mathrm{~N}$ & 145.5 & $\pm 1.4( \pm 1.0 \%)$ & 140.5 & $\pm 2.1( \pm 1.5 \%)$ & 69.7 & $\pm 2.9( \pm 4.2 \%)$ & 99.4 & $\pm 1.7( \pm 1.7 \%)$ \\
\hline $200 \mathrm{~N}$ & 195.5 & $\pm 1.9( \pm 1.0 \%)$ & 190.5 & $\pm 2.9( \pm 1.5 \%)$ & 97.5 & $\pm 3.9( \pm 4.0 \%)$ & 134.8 & $\pm 2.3( \pm 1.7 \%)$ \\
\hline
\end{tabular}

\section{CONCLUSIONS}

The measurement uncertainty for transversal force is in both load scenarios less than $1.5 \% . M_{x}$ has a maximum measurement uncertainty at $50 \mathrm{~N}$ with $6.4 \%$ whereas the measurement uncertainty of $M_{z}$ is $1.7 \%$ at all load steps. This means, the aimed uncertainty less than $1 \%$ is not achieved yet. In Table 8 the MUB of $M_{x}$ is mainly dominated by $\delta_{\mathrm{BM} / \mathrm{TM}}$. It must be considered to use a more sophisticated model equation to describe the measurement uncertainty of the inclination measurements. The uncertainty of $M_{Z}$ depends greatly on friction and the mass calibration uncertainty. Thus, it must be investigated if friction measurement can be improved.

\section{SUMMARY}

The calibration set-up for calibrating transversal force, bending moments and torque was presented. The measurement uncertainty budget of the calibration load was investigated. The characterisation of the applied force and the measurement of geometrical elements were characterised. This paper showed that the key factors are mass, friction and geometrical elements measurements whose uncertainty must be reduced either by experimental investigation or more accurate model equations.

\section{REFERENCES}

[1] H. Kahmann, C. Schlegel, R. Kumme, D. Röske, "Principle and Design of a $5 \mathrm{MN} \cdot \mathrm{m}$ Torque Standard Machine", in Proc. of 23rd IMEKO TC3 Conference, Helsinki, Finland, 2017.

[2] A. Lindau, R. Kumme, A. Heiker, "Investigation in the local gravity field of a force laboratory of PTB", in Proc. of 18th IMEKO TC3 Conference, Celle, Germany, 2002.

[3] M. Hernla, "Messunsicherheit bei Koordinatenmessungen - Abschätzung der aufgabenspezifischen Messunsicherheit mit Hilfe von Berechnungstabellen”, Band 78, Expert-Verlag $\mathrm{GmbH}$.

[4] Metrodata GmbH, Manual for GUM Workbench. 